\title{
Growth and Flowering before and after Storage of African Marigold and Salvia Seedlings Stored under Different Light Conditions
}

\author{
Jeong Wook Heo ${ }^{1}$, Dong Eok Kim ${ }^{1}$, Kee Kyung Kang ${ }^{2}$, \\ Sang Hee Park, and Changhoo Chun ${ }^{4,5 *}$ \\ ${ }^{1}$ Farming Automation Division, Department of Agricultural Engineering, National Academy of Agricultural Science, \\ Rural Development Ministration, Suwon 441-707, Korea \\ ${ }^{2}$ Department of Agricultural Environment, National Academy of Agricultural Science, \\ Rural Development Administration, Suwon 441-707, Korea \\ ${ }^{3}$ Department of Mechanical Engineering, Kumoh National Institute of Technology, Gumi 730-701, Korea \\ ${ }^{4}$ Departemnt of Plant Science, Seoul National University, Seoul 151-921, Korea \\ ${ }^{5}$ Research Institute for Agriculture and Life Sciences, Seoul National University, Seoul 151-921, Korea
}

\begin{abstract}
This study was conducted to investigate the growth and flowering of African marigold (Tagetes erecta L.) and salvia (Salvia splendens F. Sello ex Ruem \& Schult.) seedlings before and after storage under fluorescent lamps and green LED radiation conditions with different light intensities during storage. The both seedlings were kept under a storage room controlled at $8^{\circ} \mathrm{C}$ air temperature and $40 \pm 10 \%$ relative humidity conditions. Light intensities were maintained at 15 and $30 \mu \mathrm{mol} \cdot \mathrm{m}^{-2} \cdot \mathrm{s}^{-1}$ during storage. In lighting treatments, dry weight of African marigold at 28 days after storage was not significantly different, and decreased approximately $29 \%$ compared to pre-storage under dark treatment. There was no significant difference in the leaf area of salvia seedlings stored under dark condition compared to before storage, but the leaf area under green light radiation with higher light intensity (treatment $\mathrm{GH}$ ) was two times greater than before storage. The survival rate after transplanting of African marigold stored under dark condition was $10 \%$, and days to flowering increased compared to those stored under fluorescent and green light with higher light intensity (treatment FLH, GH). Comparing to before storage, growth and flowering of the both seedlings after storage were significantly promoted by the light exposure during storage. The present experimental results show that the light intensity should be decided to maintain minimum growth during lighting storage and storage quality of the seedlings such as flowering promotion and extended blooming period after lighting treatment during storage period from the above results.
\end{abstract}

Additional key words: blooming period, days to flowering, light quality, net photosynthetic rate

\section{Introduction}

Low-temperature storage of seedlings in vegetables or bedding plants is probably necessary for a few days or weeks when their growth is desired to maintain at similar level of photosynthesis and respiration rates. Because storage in transplant production was no conventionally sufficient light environment (i.e., darkness), photosynthesis was limited during storage and survival rate was to be low after transplanting (Kubota \& Kozai, 1994). Therefore, it is necessary that photosynthesis and minimum growth can be achieved by improving light environment at the lower plant leaves during storage. Investigations on storage of bedding plants were mainly conducted by controlling the storage temperature and radiation (Heins and Lange, 1992; Heins and Wallace, 1993; Heins et al., 1995; Kubota and Kozai, 1995; Kubota et al., 2002).

It was found that light quality influenced stem elongation, leaf extension, flower stalk elongation, pigmentation, or flowering of in vitro and ex vitro plant species (Heo et al.,

\footnotetext{
*Corresponding author: changhoo@snu.ac.kr

※ Received 17 November 2012; Revised 7 March 2013; Accepted 12 March 2013. This study was carried out with the support of 'Research Program for Agricultural Science \& Technology Development (Project No. PJ907067)', National Academy of Agricultural Science, Rural Development Administration, Republic of Korea. We would like to thank Dr. H. N. Murthy of Karantak University for their critical comments during the manuscript preparation.
} 
2002, 2003, 2006, 2009, 2010; Shin et al., 2003). Blue or red light is mainly absorbed by plant leaves but green light is reflected or transmitted on plant leaves. Transmitted green light plays a role in maintenance of photosynthesis at a minimum under light compensation point to show equal photosynthetic rate and respiration rate. Deterioration in plant leaves can be inhibited during storage and gave a transplant quality after storage. Effects of light quality during storage were shown by Kubota and Rajapakse (1996) and Kubota et al. (1997) also studied the response of broccoli and hosta plants stored under red, blue and white light at low temperature. However, the responses to the light qualities were different with plant species.

In the experiment, responses of marigold and salvia plug seedlings to the light during a few weeks storage under conditions of fluorescent and green lighting with different light intensities were studied in order to consider differences in growth and flowering characteristics to green light quality before and after storage.

\section{Materials and Methods}

\section{Plant Materials and Culture Box}

African marigold (Tagetes erecta L. 'Orange Boy') and salvia (Salvia splendens F. Sello ex Ruem \& Schult. 'Red Vista') seedlings which developed two true leaves were used for plant materials. Plant heights of African marigold and salvia seedlings before storage were measured at 3.6 and $2.2 \mathrm{~cm}$ in average, respectively. The seedlings were cultured at plug trays of 200 holes, and stored in polypropylene boxes (4.8 $\mathrm{L}$ in air volume) with a transparent lid under a storage room (Fig. 1). Number of air exchanges of the storage box

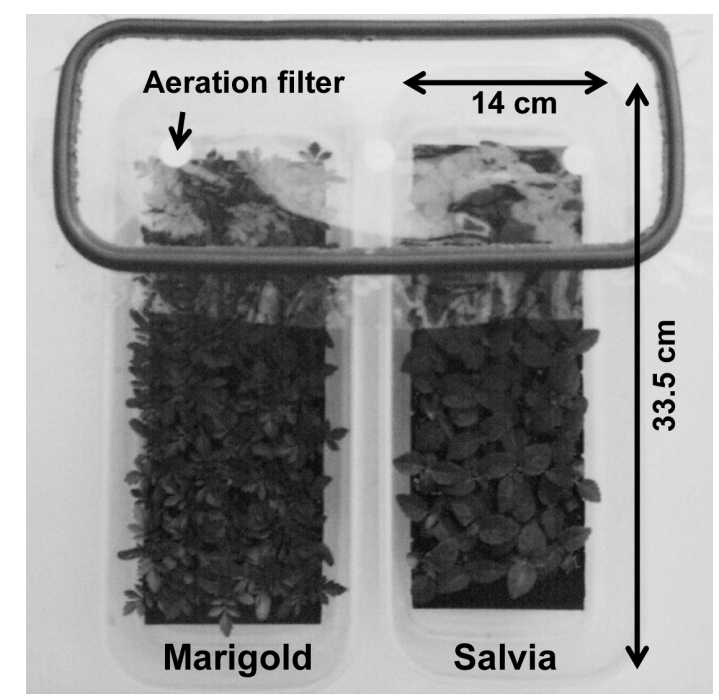

Fig. 1. Plant materials kept at the polypropylene boxes with a lid before storage. was estimated to be $1.2 \mathrm{~h}^{-1}$ according to the method described by Kozai et al. (1986).

\section{Storage Room Conditions}

Storage room was kept at $8^{\circ} \mathrm{C}$ air temperature, $40 \pm 10 \%$ relative humidity, and $16 \mathrm{~h} \cdot \mathrm{d}^{-1}$ photoperiod, respectively. $\mathrm{CO}_{2}$ concentration of the storage room was maintained at ambient conditions during the storage. Cool-white fluorescent lamp (20W FL20SSEX-W, Osram, Germany) and green LEDs (20W LED panel system, SJ I \& C Co. Ltd., Korea) were used as light sources for the seedlings storage during storage period. Five treatments with different light sources and light intensities were compared: 1) dark as a control (Treatment D), 2) fluorescent lamp with lower and higher (Treatment FLL, FLH), 3) green light (peak at $540 \mathrm{~nm}$ ) provided by LED of lower and higher PPF (Treatment GL, GH). Photosynthetic photon fluxes from the light sources on the lid of the storage boxes were maintained at 15 and $30 \pm 5$ $\mu \mathrm{mol} \cdot \mathrm{m}^{-2} \cdot \mathrm{s}^{-1}$ in all the light treatments during photoperiod. Because salvia seedlings were started to show the symptom of cold stress in several leaves, storage finished on day 21 , and African marigold maintained for 28 days under the storage room.

\section{Measurements}

Before storage under different radiation conditions, fresh weight, dry weight, plant height, and leaf area per seedling were measured to compare the growth characteristics between before and after storage. Dry weights of African marigold and salvia were respectively recorded at 187.3 and 138.9 mg per seedling before storage. On days 21 and 28 after storage, fresh weight, dry weight, leaf area, and plant height per plant of randomly selected seedlings were also measured. Number of flowering buds and open flowers, days to flowering, and blooming period were recorded after seedling storage. Dry weights before and after storage were determined when oven-dried at $70^{\circ} \mathrm{C}$ until the seedlings reached constant mass. Area of unfolded leaves was also measured with a leaf area meter (Skye Instruments Ltd., UK). Net photosynthetic rate (NPR) per seedling of salvia and African marigold at 21 and 28 days after storage in all the treatments was estimated by multiplying the difference in $\mathrm{CO}_{2}$ concentration between inside and outside of the storage in light and dark period according to the method of Fujiwara et al. (1987).

\section{Statistical Analysis}

Twenty samples from the seedlings were harvested for destructive measurement after storage and transplanting. Statistical analysis was performed using SAS software (Version 
6.21; SAS Institute Inc., Cary, NC, USA). Data were analyzed by means of analysis of variance (ANOVA), and the means were compared by the Duncan's multiple range test at $P$ $=0.05$.

\section{Results}

\section{Growth before and after Storage}

There was no significant difference in fresh weight of African marigold and salvia seedlings stored under the different light intensity conditions, but significantly increased compared to before storage in all the light treatments (Fig. 2 and Table 1). Dry weight of African marigold seedlings was not affected by the light qualities during the storage, and decreased under dark condition comparing to before storage. On the other hand, the dry weight after storage in salvia seedlings increased under green light regardless of light intensity. There was not significantly different in dry weight of the seedlings before and after storage under dark conditions. Expansion of leaf area in African marigold at 28 days after storage was limited under dark condition and stimulated under green light conditions. Leaf area was twice expended by green-light exposure during low-temperature storage compared to that of pre-storage. In African marigold stored under fluorescent or green light, there was no significant difference in leaf expansion according to the light intensity. Dark treatment for 21 or 28 days under lower temperature condition was not significant on leaf area between pre- and post-storage in African marigold and salvia seedlings.

Green radiation during the storage period significantly affected shoot growth of African marigold and salvia seedlings (Fig. 3). Plant height in African marigold 28 days after storage in the FLH, GL, and GH treatments concluding dark condition was higher compared to before storage. On day 21, shoot elongation of salvia seedlings was inhibited under dark treatment compared to other treatments and stimulated by green light regardless of light intensity. Number of internodes in African marigold and salvia seedlings was increased under FLH, GL, and GH treatments, and recorded at 4 in the treatment showing higher plant height (data not shown).

Time courses of net photosynthetic rate (NPR) per seedling of African marigold and salvia 21 and 28 days after storage were shown in Fig. 4. On day 28, respiration rate of African marigold during dark period was significantly higher under

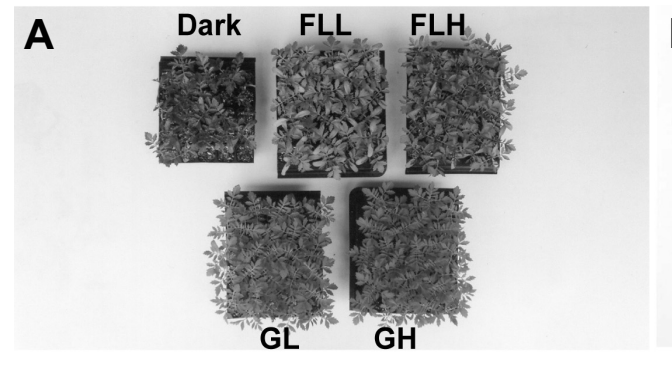

28 days after storage

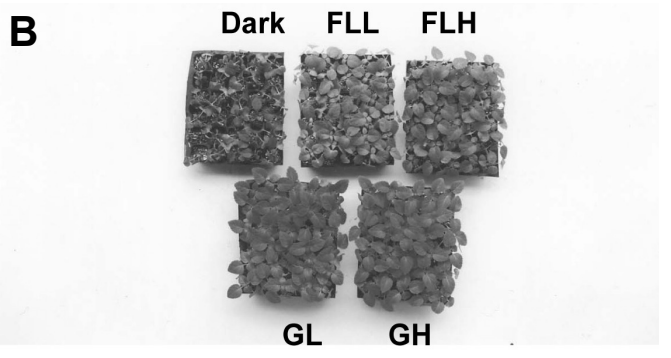

21 days after storage

Fig. 2. African marigold $(A)$ and salvia $(B)$ seedlings stored for 28 and 21 days under different light qualities and intensities. $D$, control (darkness); FLL, fluorescent lamp of $15 \mu \mathrm{mol} \cdot \mathrm{m}^{-2} \cdot \mathrm{s}^{-1} \mathrm{PPF} ; \mathrm{FLH}$, fluorescent lamp of $30 \mu \mathrm{mol} \cdot \mathrm{m}^{-2} \cdot \mathrm{s}^{-1} \mathrm{PPF}$. GL, green light provided by light-emitting diode (LED) of $15 \mu \mathrm{mol} \cdot \mathrm{m}^{-2} \cdot \mathrm{s}^{-1} \mathrm{PPF} ; \mathrm{GH}$, green light provided by LED of $30 \mu \mathrm{mol} \cdot \mathrm{m}^{-2} \cdot \mathrm{s}^{-1} \mathrm{PPF}$.

Table 1. Fresh weight, dry weight, and leaf area of African marigold and salvia seedlings stored for 28 and 21 days, respectively, under different light sources and intensities.

\begin{tabular}{|c|c|c|c|c|c|c|}
\hline \multirow[b]{2}{*}{ Treatment $^{z}$} & \multicolumn{3}{|c|}{ African marigold } & \multicolumn{3}{|c|}{ Salvia } \\
\hline & $\begin{array}{l}\text { Fresh wt. } \\
\quad(\mathrm{mg})\end{array}$ & $\begin{array}{c}\text { Dry wt. } \\
\text { (mg) }\end{array}$ & $\begin{array}{l}\text { Leaf area } \\
\left(\mathrm{cm}^{2}\right)\end{array}$ & $\begin{array}{l}\text { Fresh wt. } \\
\quad(\mathrm{mg})\end{array}$ & $\begin{array}{c}\text { Dry wt. } \\
\text { (mg) }\end{array}$ & $\begin{array}{l}\text { Leaf area } \\
\quad\left(\mathrm{cm}^{2}\right)\end{array}$ \\
\hline $\mathrm{D}$ & $166.4 c^{y}$ & $25.4 \mathrm{~b}$ & $4.2 \mathrm{c}$ & $119.2 \mathrm{~d}$ & $17.1 \mathrm{c}$ & $3.5 \mathrm{~d}$ \\
\hline FLL & $217.0 \mathrm{~b}$ & 48.3 a & $6.2 \mathrm{~b}$ & $172.2 \mathrm{c}$ & $26.5 \mathrm{~b}$ & $6.1 \mathrm{c}$ \\
\hline FLH & $213.0 \mathrm{~b}$ & $45.0 \mathrm{a}$ & $6.3 \mathrm{~b}$ & $190.6 \mathrm{~b}$ & $28.2 \mathrm{a}$ & $6.4 \mathrm{c}$ \\
\hline $\mathrm{GL}$ & $256.8 \mathrm{a}$ & $43.5 \mathrm{a}$ & $7.8 \mathrm{a}$ & $204.0 \mathrm{a}$ & $30.0 \mathrm{a}$ & $6.6 \mathrm{bc}$ \\
\hline $\mathrm{GH}$ & 549.8 a & 48.2 a & $7.7 \mathrm{a}$ & $214.6 \mathrm{a}$ & $27.1 \mathrm{a}$ & $7.4 \mathrm{a}$ \\
\hline
\end{tabular}

${ }^{\mathrm{z}} \mathrm{D}$, dark storage (control); FLL, fluorescent lamp of $15 \mu \mathrm{mol} \cdot \mathrm{m}^{-2} \cdot \mathrm{s}^{-1} \mathrm{PPF} ; \mathrm{FLH}$, fluorescent lamp of $30 \mu \mathrm{mol} \cdot \mathrm{m}^{-2} \cdot \mathrm{s}^{-1} \mathrm{PPF} ; \mathrm{GL}$, green light provided by light-emitting diode of $15 \mu \mathrm{mol} \cdot \mathrm{m}^{-2} \cdot \mathrm{s}^{-1} \mathrm{PPF} ; \mathrm{GH}$, green light provided by light-emitting diode of $30 \mu \mathrm{mol} \cdot \mathrm{m}^{-2} \cdot \mathrm{s}^{-1}$ PPF.

${ }^{y}$ Different letter indicates significantly different at the $5 \%$ level by Duncan's multiple range test. 

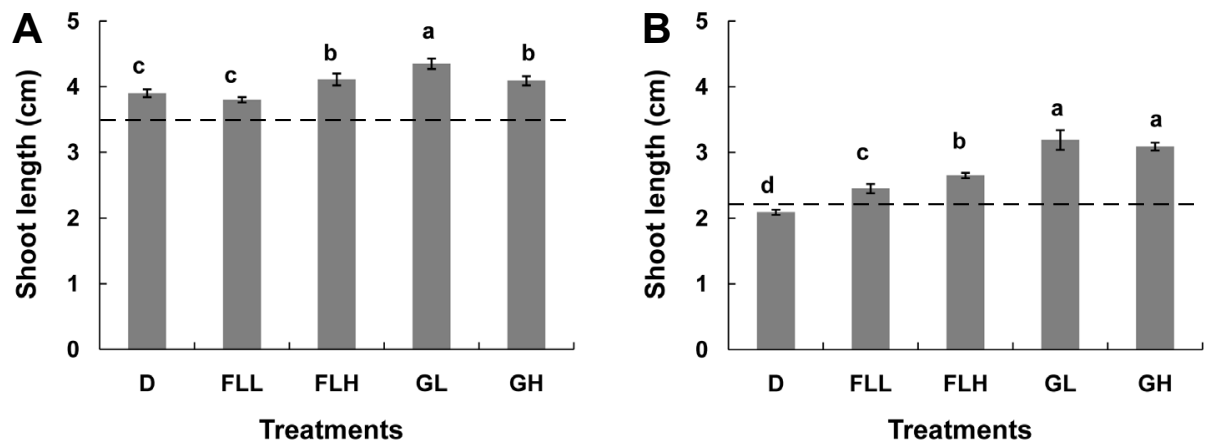

Fig. 3. Plant height after storage of African marigold (A) and salvia (B) seedlings stored for 28 and 21 days, respectively, as affected by different light source and intensity. The dotted lines mean plant height before storage. D, control; FLL, fluorescent lamp of $15 \mu \mathrm{mol} \cdot \mathrm{m}^{-2} \cdot \mathrm{s}^{-1} \mathrm{PPF} ; \mathrm{FLH}$, fluorescent lamp of $30 \mu \mathrm{mol} \cdot \mathrm{m}^{-2} \cdot \mathrm{s}^{-1} \mathrm{PPF}$. GL, green light provided by light-emitting diode of $15 \mu \mathrm{mol} \cdot \mathrm{m}^{-2} \cdot \mathrm{s}^{-1} \mathrm{PPF} ; \mathrm{GH}$, green light provided by light-emitting diode of $30 \mu \mathrm{mol} \cdot \mathrm{m}^{-2} \cdot \mathrm{s}^{-1} \mathrm{PPF}$. Vertical bars represent standard error $(n=20)$. ${ }^{2}$ Different letter indicates the significantly difference at the $5 \%$ level by Duncan's multiple range test.

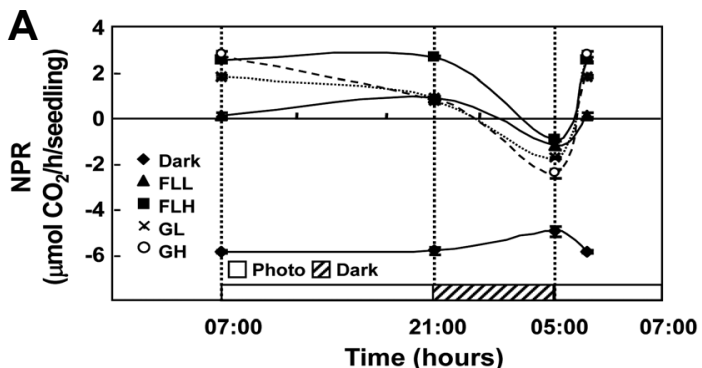

B

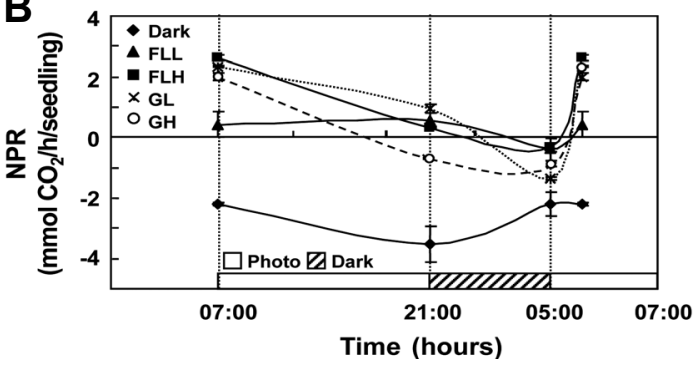

Fig. 4. Time course of net photosynthetic rate (NPR) in African marigold $(A)$ and salvia $(B)$ seedlings as affected by different light source and intensity during storage period. D, control; $\mathrm{FLL}$, fluorescent lamp of $15 \mu \mathrm{mol} \cdot \mathrm{m}^{-2} \cdot \mathrm{s}^{-1} \mathrm{PPF} ; \mathrm{FLH}$, fluorescent lamp of $30 \mu \mathrm{mol} \cdot \mathrm{m}^{-2} \cdot \mathrm{s}^{-1} \mathrm{PPF}$. GL, green light provided by light-emitting diode of $15 \mu \mathrm{mol} \cdot \mathrm{m}^{-2} \cdot \mathrm{s}^{-1} \mathrm{PPF} ; \mathrm{GH}$, green light provided by light-emitting diode of $30 \mu \mathrm{mol} \cdot \mathrm{m}^{-2} \cdot \mathrm{s}^{-1} \mathrm{PPF}$. Vertical bars represent standard error $(n=20)$. dark treatment than under lighting storage treatments for a day. Under darkness storage condition, respiration rate in both of the seedlings was stable around -6 and $-2 \mu \mathrm{mol} \cdot \mathrm{CO}_{2} \cdot \mathrm{h}^{-1}$, although respiration rate slightly increased during dark period compared to that during light period. NPR of African marigold or salvia seedlings was tend to be steadily decreased from starting of the dark period in all the lighting treatments, and recovered together with photoperiod starting excepting for dark treatment. NPR of the seedlings was improved by GH or FLH treatment with the higher PPF than the lower PPF treatments.

As shown in Fig. 5, sugar synthesis in the seedlings during the storage was significantly stimulated under FLL treatment showing the NPR of nearly zero, but inhibited under dark treatment. Light intensities of green light tested in the experiment during the storage did not influence sugar accumulation in the seedlings. Sugar contents in both of the seedlings were more than 2 times greater under FLL treatment of lower PPF compared to others.

Flowering Characteristics after Storage (after Transplantation)

Increment of number of flower buds and open flowers
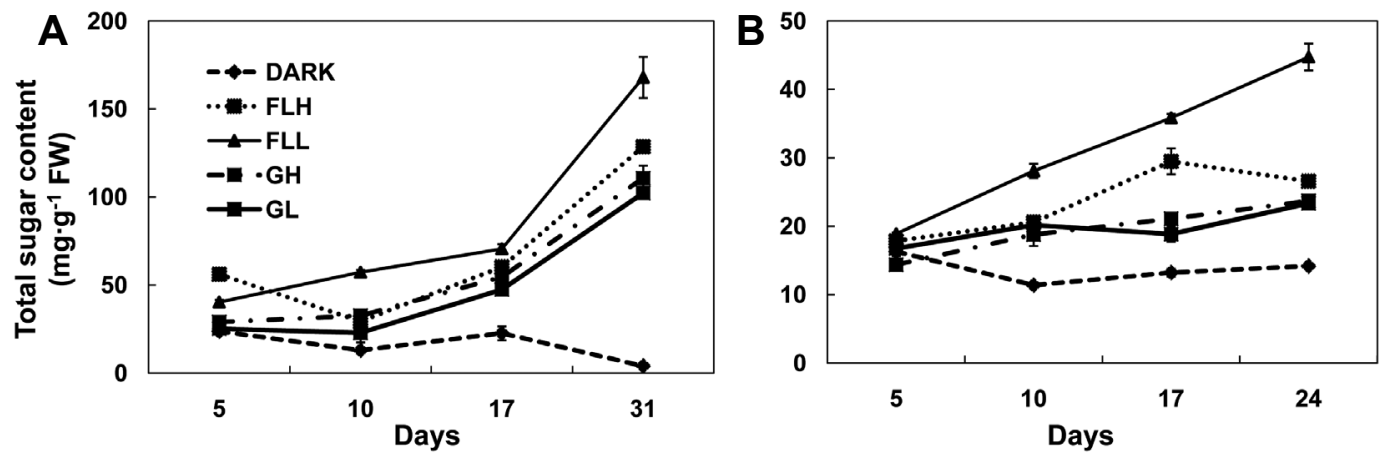

Fig. 5. Time course of total sugar contents of African marigold $(A)$ and salvia $(B)$ seedlings as affected by different light source and intensity during storage period. D, control; FLL, fluorescent lamp of $15 \mu \mathrm{mol} \cdot \mathrm{m}^{-2} \cdot \mathrm{s}^{-1} \mathrm{PPF} ; \mathrm{FLH}$, fluorescent lamp of $30 \mu \mathrm{mol} \cdot \mathrm{m}^{-2} \cdot \mathrm{s}^{-1}$ PPF. GL, green light provided by light-emitting diode of $15 \mu \mathrm{mol} \cdot \mathrm{m}^{-2} \cdot \mathrm{s}^{-1} \mathrm{PPF} ; \mathrm{GH}$, green light provided by light-emitting diode of $30 \mathrm{\mu mol} \cdot \mathrm{m}^{-2} \cdot \mathrm{s}^{-1} \mathrm{PPF}$. Vertical bars represent standard error $(\mathrm{n}=20)$. 
were affected by GH treatment in African marigold (Fig. 6 and Table 2) 42 days after transplanting. Number of flower buds in FLH and GH was approximately 14 and 18 times greater than in $\mathrm{D}$ treatment. There was no significant difference in number of open flowers of African marigold among the
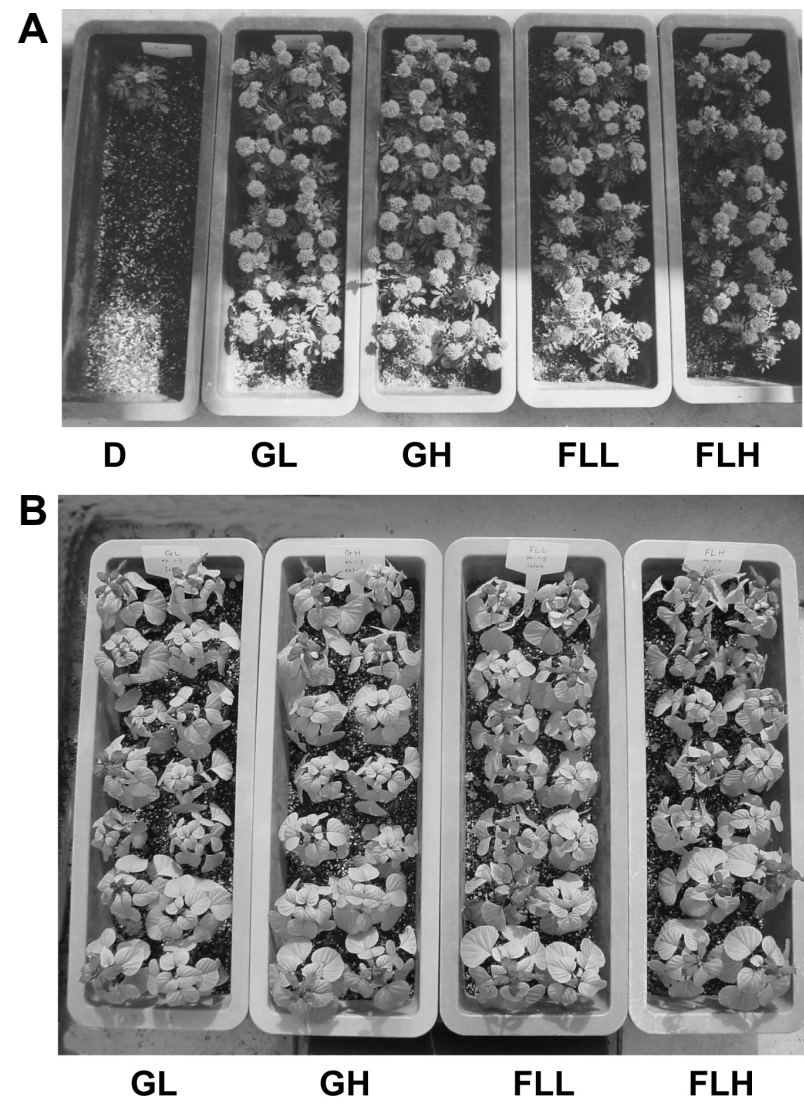

Fig. 6. Flowering of African marigold (A) and salvia (B) seedlings grown under greenhouse conditions for 60 days after storage. $\mathrm{D}$, control; FLL, fluorescent lamp of $15 \mu \mathrm{mol} \cdot \mathrm{m}^{-2} \cdot \mathrm{s}^{-1} \mathrm{PPF}$; FLH, fluorescent lamp of $30 \mu \mathrm{mol} \cdot \mathrm{m}^{-2} \cdot \mathrm{s}^{-1} \mathrm{PPF}$. GL, green light provided by light-emitting diode of $15 \mu \mathrm{mol} \cdot \mathrm{m}^{-2} \cdot \mathrm{s}^{-1} \mathrm{PPF} ; \mathrm{GH}$, green light provided by light-emitting diode of $30 \mu \mathrm{mol} \cdot \mathrm{m}^{-2} \cdot \mathrm{s}^{-1}$ PPF. lighting treatments, but considerably increased compared with D treatment.

In salvia seedlings, flowering bud was not observed in D treatment because all of the stored seedlings was etiolated 3 days after transplanting. Under light treatments, formation of flower buds in salvia was stimulated by the green light as well as in African marigold. However, significant promotion in number of open flowers was not affected by the light treatments for 42 days after transplanting.

Days to flowering in African marigold were delayed under darkness storage conditions and not significantly different among the light treatments (Table 3). First flowering of African marigold stored under GH treatment was observed 16 days after transplanting, and the open flowers were bloomed for 25 days. In GL and GH treatments, days to first flowering of salvia were 46 and the open flowers were still blooming until the final day of the experiment.

\section{Discussion}

Growth and flowering characteristics before and after storage of African marigold and salvia seedlings were studied under fluorescent and green LED lights during storage period. Compared to African marigold, salvia 'Red Vista' seedlings after 21-days storage deteriorated under darkness and cotyledons were to be yellowing in plant leaves. In salvia 'Red Hot Sally', it was found that the optimum temperature for storage in the dark and light conditions was $5^{\circ} \mathrm{C}$ during 6 weeks (Heins et al., 1995). Flowering physiology in several plant species can be influenced by lower temperature treatment. In this study, although the seedling storage was stopped on 3 weeks after light treatment in the 'Red Vista' because of deterioration in the darkness condition excepting for the light treatments.

However, the storage duration in the seedlings can be

Table 2. Number of flower buds and open flowers of African marigold and salvia seedlings grown under greenhouse conditions for 60 days after storage.

\begin{tabular}{|c|c|c|c|c|}
\hline \multirow{2}{*}{ Treatment $^{2}$} & \multicolumn{2}{|c|}{ African marigold } & \multicolumn{2}{|c|}{ Salvia } \\
\hline & No. of buds & NO. open flowers & No. of buds & NO. open flowers \\
\hline $\mathrm{Dz}$ & $2 d^{y}$ & $1 \mathrm{~b}$ & $-x$ & $-w$ \\
\hline FLL & $25 c$ & $43 a$ & $3 \mathrm{~b}$ & 2 \\
\hline FLH & $27 \mathrm{c}$ & $40 \mathrm{a}$ & $2 \mathrm{~b}$ & 1 \\
\hline GL & $33 \mathrm{~b}$ & $40 a$ & $5 a$ & 1 \\
\hline $\mathrm{GH}$ & $36 a$ & $41 \mathrm{a}$ & $6 a$ & 2 \\
\hline
\end{tabular}

${ }^{\mathrm{z}} \mathrm{D}$, control; FLL, fluorescent lamp of $15 \mu \mathrm{mol} \cdot \mathrm{m}^{-2} \cdot \mathrm{s}^{-1} \mathrm{PPF} ; \mathrm{FLH}$, fluorescent lamp of $30 \mu \mathrm{mol} \cdot \mathrm{m}^{-2} \cdot \mathrm{s}^{-1} \mathrm{PPF}$; GL, green light provided by light-emitting diode of $15 \mu \mathrm{mol} \cdot \mathrm{m}^{-2} \cdot \mathrm{s}^{-1} \mathrm{PPF} ; \mathrm{GH}$, green light provided by light-emitting diode of $30 \mu \mathrm{mol} \cdot \mathrm{m}^{-2} \cdot \mathrm{s}^{-1} \mathrm{PPF}$.

${ }^{y}$ In a column, the mean values followed by a different letter are significantly different at the $5 \%$ level by Duncan's multiple range test.

${ }^{x}$ No seedling was survived on day 60 after transplantation.

${ }^{\mathrm{w}}$ Not blooming. 
Table 3. Days to flowering and blooming period of African marigold and salvia seedlings grown under greenhouse conditions for 60 days after storage.

\begin{tabular}{|c|c|c|c|c|}
\hline \multirow{2}{*}{ Treatment $^{z}$} & \multicolumn{2}{|c|}{ African marigold } & \multicolumn{2}{|c|}{ Salvia } \\
\hline & Days to flowering & Blooming period & Days to flowering & Blooming period \\
\hline$D$ & $45 a^{y}$ & $14 \mathrm{~b}$ & $-x$ & $-w$ \\
\hline FLL & $18 \mathrm{~b}$ & $25 \mathrm{a}$ & 46 & - \\
\hline FLH & $17 \mathrm{~b}$ & $26 a$ & 47 & - \\
\hline GL & $17 \mathrm{~b}$ & $26 a$ & 46 & - \\
\hline $\mathrm{GH}$ & $16 \mathrm{~b}$ & $25 a$ & 48 & - \\
\hline
\end{tabular}

${ }^{\mathrm{Z}} \mathrm{D}$, darkness (control); FLL, fluorescent lamp of $15 \mu \mathrm{mol} \cdot \mathrm{m}^{-2} \cdot \mathrm{s}^{-1} \mathrm{PPF} ; \mathrm{FLH}$, fluorescent lamp of $30 \mu \mathrm{mol} \cdot \mathrm{m}^{-2} \cdot \mathrm{s}^{-1} \mathrm{PPF} ; \mathrm{GL}, \mathrm{green}$ light provided by light-emitting diode of $15 \mu \mathrm{mol} \cdot \mathrm{m}^{-2} \cdot \mathrm{s}^{-1} \mathrm{PPF} ; \mathrm{GH}$, green light provided by light-emitting diode of $30 \mu \mathrm{mol} \cdot \mathrm{m}^{-2} \cdot \mathrm{s}^{-1}$ PPF.

${ }^{y}$ Different letter indicates significantly different at the $5 \%$ level by Duncan's multiple range test.

${ }^{x}$ No seedling under dark condition was survived 60 days after storage (transplanting).

${ }^{\mathrm{w}}$ The flowers were still blooming 60 days after transplanting.

longer than 3 weeks under fluorescent or green light treatments in the base of normal growth and flowering after transplanting under $8^{\circ} \mathrm{C}$ air temperature condition compared with the above previous studies. Resistance to the low temperature and light stimulation for storage period in African marigold 'Orange Boy' was remarkable compared to that in salvia seedlings. But, one plant among 24 transplants was only survived until 60 days and bloomed after 28-days storage under dark treatment. Thus, storage duration in African marigold 'Orange Boy' should be shorter than 4 weeks compared to the results on 21-days storage of African marigold 'Hero Yellow' in dark storage (Heins et al., 1995). Currently, African marigold 'Hero Yellow' transplants in light condition could be stored for 6 weeks without any visual quality deterioration in their commercial value (Heins et al., 1995). Light treatment by fluorescent or green LED light has been shown to be effective for maintaining the seedling quality after storage of African marigold for 28 days, and storage duration could be delayed more than 4 weeks. It is suggested that the storage duration can be changed according to plant species and cultivar.

When broccoli plantlets transplanted after photoautotrophic culture were stored under darkness for 6 weeks, all the plantlets died during the acclimatization stage compared with under lighting condition of red, blue and white (Kubota et al., 1997). However, there was no significant difference in the different light qualities and radiation during storage maintained plantlet growth such as dry weight and carbohydrate levels.

In African marigold and salvia seedlings, sugar synthesis was significantly stimulated by fluorescent or green light treatment, and dark treatment gave the lowest sugar contents. However, there was no significant difference under green light quality with 15 or $30 \mu \mathrm{mol} \cdot \mathrm{m}^{-2} \cdot \mathrm{s}^{-1} \mathrm{PPF}$ conditions.
Otherwise, effects of light treatment during storage on chemical component metabolism in spinach or komastuna plants were revealed by Toledo et al. (2003) and Hosoda et al. (2000). The results showed even though there was no significant difference in enzyme activities between light and dark treatment, soluble carbohydrates and glucose contents in the leaves increased under light condition during storage.

Present results also showed the information about effect of green LED radiation on seedling quality such as growth and flowering characteristics after lighting storage. Formation of flower buds or extension of blooming period was promoted by green light treatment even though sugar-synthesis ability was lower comparing to fluorescent light. It means that chemical system such as a carbohydrate metabolism, ascorbic acid, or enzyme activity including plant growth after storage can be stimulated by light exposure during storage (e.g., Morais et al., 2002; Nielsen et al., 1997; Siomos et al., 2000). Low temperature storage of African marigold and salvia seedlings under lighting conditions with a lower light intensity affects seedling quality such as a growth, flowering, or blooming period before or after storage. Green light quality during the storage was particularly beneficial for development of flower buds in the seedlings after storage. Under darkness, growth of the seedlings before and after storage was not significantly different from the treatments. However, the salvia seedlings in all the treatments were etiolated on day 3 after transplanting and one plant of African marigold was only survived until 60 days. According to the improved growth during the storage under lighting treatments, i. e., light compensation point, the light intensity to inhibit the growth and to keep identically the NPR and respiration rate during storage should be lower compared with this experimental condition.

The results indicate that it is important to consider the reasonable light intensity of light source or light quality using 
for low temperature storage for maintaining the horticultural value such as weight and leaf area before and after storage. Further investigation will study the developmental effects of different green-light intensities that would maintain identical NPR and respiration rate of several seedlings before and after storage of the seedlings under several light intensity and temperature conditions.

\section{Literature Cited}

Fujiwara, K., T. Kozai, and I. Watanabe. 1987. Fundamental studies on environments in plant tissue culture vessels. (3) Measurements of carbon dioxide gas concentration in stoppered vessels containing tissue cultured plantlets and estimates of net photosynthetic rates of the plantlets. J. Agri. Met. 43:21-30.

Heins, R.D. and N. Lange. 1992. How to store salvia and ageratum plugs. Greenhouse Grower Feb.:76-82.

Heins, R.D. and T.F. Wallace, Jr. 1993. How to store Alyssum plugs. Greenhouse Grower Mar.:32-33.

Heins, R.D., M.P. Kaczperski, T.F. Wallace, Jr., N.E. Lange, W.H. Calson, and J.A. Flore. 1995. Low-temperature storage of bedding plants plugs. Acta Hort. 396:285-296.

Heo, J., C. Lee, D. Chakrabarty, and K. Paek. 2002. Growth responses of marigold and salvia bedding plants as affected by monochromic or mixture radiation provided by a lightemitting diode (LED). Plant Growth Regul. 38:225-230.

Heo, J., C. Lee, H.N. Murthy, and K. Paek. 2003. Influence of light quality and photoperiod on flowering of Cyclamen persicum Mill. cv. 'Dixie White'. Plant Growth Regul. 40:7-10.

Heo, J., C. Lee, and K. Paek. 2006. Influence of mixed LED radiation on the growth of annual plants. J. Plant Biol. 49: 286-290.

Heo, J., K. Shin, S. Kim, and K. Paek. 2006. Light quality affects in vitro growth of grape 'Teleki 5BB'. J. Plant Biol. 49:276-280.

Heo, J., Y. Lee, D. Lee, and C. Chun. 2009. Light quality affects growth, net photosynthetic rate, and ethylene production of ageratum, African marigold, and salvia seedlings. Kor. J. Hort. Sci. Technol. 27:187-193.

Heo, J., Y. Lee, D. Kim, Y. Chang, and C. Chun. 2010. Effects of supplementary LED lighting on growth and biochemical parameters in Diffenbachia amoena 'Camella' and Ficus elastic 'Melany'. Kor. J. Hort. Sci. Technol. 28:51-58.
Hosoda, H., Y. Nawa, and M. Kurogi. 2000. Effect of light quality on postharvest changes of chemical components in komastuna (Brassica campestris L.) leaves. Food Preservation Sci. 26:15-18.

Kozai, T., K. Hujiwara, and I. Watanabe. 1986. Fundamental studies on environments in plant tissue culture vessels. (2) Effects of stoppers and gas exchange rates between inside and outside vessels closed with stopper. J. Agri. Met. 42:119-127.

Kubota, C. and T. Kozai. 1994. Low temperature storage for quality preservation and growth suppression of broccoli plantlets cultured in vitro. HortScience 29:1191-1194.

Kubota, C. and T. Kozai. 1995. Low-temperature storage of transplants at the light compensation point: air temperature and light intensity for growth suppression and quality preservation. Sci. Hort. 61:193-204.

Kubota, C. and N.C. Rajapakse. 1996. Low-temperature storage of micropropagated plantlets under selected light environments. HortScience 31:449-452.

Kubota, C., N.C. Rajapakse, and R.E. Young. 1997. Carbohydrate status and transplant quality of micropropagated broccoli plantlets under stored different light environments. Postharvest Biol. Technol. 12:165-173.

Kubota, C., S. Seiyama, and T. Kozai. 2002. Manipulation of photoperiod and light intensity in low-temperature storage of eggplants plug seedlings. Sci. Hort. 94:13-20.

Morais, H., C. Ramos, E. Forgacs, T. Cserhati, and J. Oliviera. 2002. Influence of storage conditions on the stability of monomeric anthocyanins studied by reversed-phase highperformance liquid chromatography. J. Chromatography B 770:297-301.

Nielsen, T.H., U. Deiting, and M. Stitt. 1997. A $\beta$-amylase in potato tubers is induced by storage at low temperature. Plant Physiol. 113:503-510.

Shin, K.S., H.N. Murthy, J.W. Heo, and K. Paek. 2003. Induction of betalain pigmentation in hairy roots of red beet under different radiation sources. Biol. Plant. 47:149-152.

Siomos, A.S., E.M. Sfakiotakis, and C.C. Dogras. 2000. Modified atmosphere package of white asparagus spears: composition, color and textural quality responses to temperature and light. Sci. Hort. 84:1-13.

Toledo, M.E.A., Y. Ueda, Y. Imahori, and M. Ayaki. 2003. L-ascorbic acid metabolism in spinach (Spinacia oleracea L.) during postharvest storage in light and dark. Postharvest Biol. Technol. 28:47-57. 